\title{
Holter ST monitoring early after acute myocardial infarction: mechanisms of ischaemia in patients treated by thrombolysis
}

\author{
Robert N Stevenson, Bradley G Marchant, Kusalagaram Ranjadayalan, \\ Subramaniam Uthayakumar, Adam D Timmis
}

\begin{abstract}
Objective-To investigate the mechanisms of Holter ST shift in patients with acute myocardial infarction treated by thrombolysis.

Design-Prospective observational study. Setting-A London district general hospital.

Subjects-The study group consisted of 94 patients with acute myocardial infarction treated by thrombolysis.

Interventions-All underwent early 48 hour Holter ST monitoring and elective coronary arteriography.

Main outcome measures-Relation of Holter ST shift to multivessel coronary disease, coronary patency, collateralisation, and morphology of the infarct related lesion.

Results-There was a trend towards an increased prevalence of Holter ST shift in patients with patency of the infarct related artery and those with multivessel disease. This was only significant in patients with three vessel disease, a significantly higher proportion of whom had $>3$ episodes of ST shift (41\% $v 14 \%$; p $=0.02$ ) or a total duration of ST shift $>1$ hour $(35 \% v 13 \% ; p=0.04)$ than those with less extensive coronary disease. Holter ST shift occurred in a significantly higher proportion of patients with complex lesion morphology (Ambrose type 2 or 3) compared with those with lesions of Ambrose morphology type 1 or $2(60 \% v 33 \% ; \mathrm{p}=0.05)$.

Conclusion-Holter ST shift detected early after thrombolysis is an ischaemic phenomenon with a complex pathophysiology. It reflects both remote ischaemia in patients with multivessel disease, and dynamic ischaemic processes related to complex lesion morphology in those with a patent infarct related artery.
\end{abstract}

(Br Heart f 1993;70:433-437)

It is now generally accepted that ST changes recorded on Holter monitoring in patients with chronic stable angina reflect myocardial ischaemia, regardless of whether or not they are accompanied by chest pain. ${ }^{1}$ The nature of Holter ST changes recorded in patients early after acute myocardial infarction is less certain, not least because of the recognised difficulty in interpreting ST segment shifts in the presence of resting electrocardiographic abnormalities. Nevertheless, a number of studies have shown Holter monitoring of ST changes after acute myocardial infarction to be of prognostic value, suggesting that ST changes are indeed ischaemic in origin. ${ }^{2-7}$ As well as these studies carried out in the prethrombolytic era, we have shown a significant relation between Holter ST shift and subsequent recurrent ischaemic events in patients with myocardial infarction treated by thrombolysis. ${ }^{8}$ Many of the recurrent events that occur early after successful thrombolysis are thought to be due to coronary reocclusion, and we have therefore suggested that ST changes detected during early Holter monitoring may reflect ischaemic processes in the infarct related artery. The mechanism of recurrent ischaemia is unknown but may relate to the morphology of the infarct related artery.

The aim of this study, therefore, was to investigate the relation between ST shift detected on 48 hour Holter monitoring and features of coronary anatomy and lesion morphology in a group of consecutive patients with acute myocardial infarction treated by thrombolysis.

\section{Patients and methods}

SELECTION OF PATIENTS

The study group was selected from a population of 176 consecutive patients who presented to Newham General Hospital and received intravenous thrombolytic treatment for acute myocardial infarction. The diagnosis of acute myocardial infarction was based on any two of three criteria-namely, typical chest pain, $\geqslant 0.1 \mathrm{mV} \mathrm{ST}$ elevation in at least one standard or two precordial leads, rise in serum creatine kinase to $>400 \mathrm{IU} / 1$. All patients were treated with streptokinase $(1 \cdot 5$ million IU infused over one hour). Specific inclusion criteria were: (a) acute myocardial infarction as defined; (b) treatment with a thrombolytic agent; $(c)$ uncomplicated course in the coronary care unit without ongoing chest pain, electrical instability, severe heart failure, or need for intravenous treatment 48 hours after completion of thrombolytic treatment; (d) no abnormalities preventing interpretation of ST changes on Holter analysis (left bundle branch block, paced rhythms, digoxin induced ST/T changes). At the time of this study, coronary arteriography was offered to all patients younger than 70 as routine clinical practice. Thus 100 patients who underwent coronary arteriography as a 
result of this clinical policy were eligible for the study. Of these, six were excluded either because they had a reinfarction during Holter monitoring (three) or because the recording was of insufficient quality for reliable ST analysis (three). Table 1 shows the clinical characteristics of the study group. The reasons for not proceeding to coronary arteriography in the remaining 76 patients were age greater than 70 (44), refusal to give consent (15), previous coronary bypass surgery (six), and death during the intervening period between Holter monitoring and cardiac catheterisation (three). In the rest the reason was not recorded.

\section{AMBULATORY ELECTROCARDIOGRAPHIC (HOLTER) MONITORING}

Patients underwent 48 hour Holter ST monitoring on average 83 hours after completion of thrombolytic treatment (range 48-180 hours). All patients needed to be free of chest pain and to be haemodynamically stable for at least 24 hours before the start of Holter monitoring. Monitoring was performed with frequency modulated dual channel recorders and high quality pre-gelled electrodes (Marquette Electronics, Milwaukee, USA). The leads monitored were chosen from a modified precordial lead (V4, V5, V6) and a modified inferior lead (II III, or aVF) avoiding those with noticeable baseline ST segment abnormalities. Leads with pathological $Q$ waves were avoided where possible. Patients were instructed in keeping a simple diary to record episodes of chest pain.

The magnetic tapes (TDK) were analysed with a commercially available computerised system (Marquette Electronics, Milwaukee, USA) after careful manual calibration and review of morphology of the electrocardiographic complex. Episodes of ST shift were identified on the computer generated trend analysis and validated manually by examination of electrocardiographic strips printed at each point of interest. Examples of baseline traces were also printed and examined at regular intervals during the analysis. All tapes were analysed by a trained investigator (RS) and electrocardiographic traces were reviewed with a second investigator (KR or BM). The tapes were reported prospectively and without knowledge of clinical outcome, recording the number and duration of episodes of ST depression and ST elevation. Significant ST depression was defined as planar or down sloping ST segment shift $\geqslant 0.1 \mathrm{mV}$ at 0.08 seconds after the $\mathrm{J}$ point that persisted for

\begin{tabular}{ll}
$\begin{array}{l}\text { Table } 1 \\
(n=94)\end{array}$ & Clinical characteristics of the study group \\
\hline Age (SEM range) (yr) & $54((10) 33-70)$ \\
Sex (men) & 87 \\
Location of infarct: & 46 \\
$\quad$ Anterior & 48 \\
Inferior & 73 \\
Q wave: & 21 \\
Q & \\
Non-Q & \\
\hline
\end{tabular}

more than one minute. Where there was preexisting ST depression, $\geqslant 0.2 \mathrm{mV}$ of additional ST depression was regarded as a significant change from baseline. Significant ST elevation was defined as upward shift of the ST segment of $\geqslant 0.2 \mathrm{mV}$ at the $\mathrm{J}$ point compared with baseline. Changes in $T$ wave vector were ignored unless accompanied by the ST segment changes described. An interval of $\geqslant 2$ minutes was required after the return of the ST segment to baseline before another discrete episode was counted. Each episode was determined to be either symptomatic or silent after review of the patient's angina diary.

\section{CARDIAC CATHETERISATION}

Patients underwent coronary arteriography and single plane (right anterior oblique) left ventriculography within two to four weeks of discharge from hospital. Multiple projections of the coronary arteries were recorded on cine film and were reviewed by two experienced observers who were blind to the results of the treadmill stress tests. Significant stenosis was defined as $>50 \%$ luminal narrowing (assessed by visual inspection) occurring in any of the three major coronary vessels or their large branches. The infarct related coronary artery was assessed by the Thrombolysis in Myocardial Infarction (TIMI) criteria. ${ }^{9}$ Patency was defined as TIMI grade 2 or 3. Collateralisation of the infarct related artery was assessed by a previously defined method ${ }^{10}$ that grades collaterals according to the extent to which the epicardial arterial segment distal to the infarct related lesion is retrogradely opacified: $0=$ no collateral vessels visible, $1=$ collateral vessels visible, $2=<50 \%$ opacification of distal segment, $3=>50 \%$ opacification of distal segment. Collateral scores of 2 or 3 were considered to represent high grade collateralisation. All angiographic data were analysed by two experienced observers (RS, BM) without knowledge of the Holter findings.

\section{ANALYSIS OF LESION MORPHOLOGY}

Analysis of lesion morphology was undertaken in all patients (60) with a patent infarct related artery at coronary angiography. For each lesion analysed, two selected orthogonal views were projected with magnification and traced by hand on to white paper. Coronary lesions were morphologically classified by the criteria of Ambrose et al ${ }^{11}$ into one of four categories: concentric (type 0); eccentric with smooth borders and a broad neck (type 1); eccentric with irregular borders or overhanging edges (type 2); diffuse lesion with multiple irregularities (type 3). All analyses were undertaken by two experienced observers (RS, BM) without knowledge of the Holter findings.

\section{MEDICATION}

All patients were prescribed $75-150 \mathrm{mg}$ aspirin daily, and at the time of Holter monitoring $47(50 \%)$ patients were taking $\beta$ blockers, $13(14 \%)$ calcium antagonists, and 15 
(16\%) long acting nitrates. No patients were prescribed digoxin.

\section{STATISTICAL ANALYSIS}

All averaged data are expressed as means (SEM). Continuous variables were checked for normal distribution and analysed with unpaired Student's $t$ tests. Categorical data were analysed by the $\chi^{2}$ or Fisher exact tests as appropriate. Statistical significance was taken as $p \leqslant 0.05$, although we have quoted marginal values $(p>0.05-<0 \cdot 1)$.

The study was approved by the local ethics committee and all patients gave informed written consent.

\section{Results}

RELATION BETWEEN HOLTER FINDINGS AND CORONARY ANATOMY

Coronary arteriography was performed in 94 patients of whom $51(54 \%)$ had multivessel disease and $17(18 \%)$ had either three vessel or left main stem disease. The infarct related artery was patent in $60(67 \%)$ of the 90 patients in whom recanalisation could be assessed. The remaining four patients who had an occluded infarct related artery had sustained a recurrent thrombotic event between Holter monitoring and cardiac catheterisation and were therefore excluded from the analysis of recanalisation.

There was a trend towards an increased prevalence of ST segment shift on Holter monitoring in patients with patency of the infarct related artery and those with multivessel disease (table 2 ). This was only significant, however, in the subgroup with three vessel disease, a significantly higher proportion of whom had more than three episodes of ST shift $(41 \% v 14 \% ; p=0.02)$ or a total duration of ST shift in excess of one hour $(35 \% v 13 \% ; \mathrm{p}=0.04)$, compared with patients with less extensive coronary disease. There was no relation overall between high grade collateralisation of the infarct related coronary artery and Holter findings. In the subgroup with ST shift during Holter monitoring and an occluded infarct related artery (nine), however, high grade collateralisation was shown in all but two patients (table 3 ).

\section{RELATION BETWEEN HOLTER FINDINGS AND} MORPHOLOGY OF THE INFARCT RELATED CORONARY LESION

Detailed analysis of coronary artery lesion morphology was undertaken in the 60 patients with a patent infarct related artery (table 4). Holter ST shift occurred in a
Table 3 Relation between Holter ST shift and high grade collateralisation in patients with an occluded infarct related coronary artery

\begin{tabular}{|c|c|c|}
\hline & \multicolumn{2}{|c|}{ Collateralisation } \\
\hline & $\begin{array}{l}\text { No } \\
(n=10) \\
n(\%)\end{array}$ & $\begin{array}{l}\text { Yes } \\
(n=20) \\
n(\%)\end{array}$ \\
\hline $\begin{array}{l}\text { No ST shift }(n=21) \\
\text { ST shift }(n=9)\end{array}$ & $\begin{array}{l}8(80) \\
2(20)\end{array}$ & $\begin{array}{l}13(65) \\
7(35)\end{array}$ \\
\hline
\end{tabular}

$\mathrm{p}=0.34$; Fisher's exact test.

Table 4 Relation between Holter findings and morphology of the infarct related coronary lesion

\begin{tabular}{lll}
\hline & $\begin{array}{l}\text { Ambrose 0 or 1 } \\
(n=40) \\
n(\%)\end{array}$ & $\begin{array}{l}\text { Ambrose } 2 \text { or } 3 \\
(n=20) \\
n(\%)\end{array}$ \\
\hline ST shift $(\mathrm{n}=25)$ & $13(33)$ & $12(60)^{\star}$ \\
$>3$ Episodes of ST shift \\
$\begin{array}{l}(\mathrm{n}=13) \\
\text { Duration of ST shift }>1 \mathrm{~h} \\
(\mathrm{n}=11)\end{array}$ & $6(15)$ & $7(35)$ \\
\hline
\end{tabular}

${ }^{\star} \mathrm{p}=0.05 ; \chi^{2}$ test.

significantly higher proportion of patients with complex lesion morphology, defined as Ambrose type 2 or 3, compared with those with lesions of Ambrose morphology type 0 or $1(60 \% v 33 \% ; p=0.05)$. There was no significant difference between complex and non-complex lesions for mean \% stenosis diameter $(77 \cdot 8 \%(2 \cdot 8) \%$ and $72 \cdot 5 \%(2 \cdot 9) \%$ respectively; $t=1 \cdot 33, \mathrm{p}=0 \cdot 19)$.

\section{Discussion}

Our results indicate that the pathophysiology of Holter ST shift early after myocardial infarction is complex and multifactorial. Nevertheless, it is clearly an ischaemic phenomenon that is related not only to extensive coronary disease, but also to the morphology of the infarct related lesion.

The angiographic data indicate that ischaemia remote from the infarct zone may be an important determinant of Holter ST shift early after myocardial infarction. Thus patients with multivessel disease tended to have a higher prevalence of Holter ST shift, and episodes were significantly more frequent and prolonged in patients with involvement of three major vessels or the left main stem. These findings are similar to those of Mulcahy et al in patients with chronic stable angina, ${ }^{12}$ but there have been few studies in patients with unstable angina or acute myocardial infarction. Those studies that are available have shown conflicting results probably because of selection bias in referral for

Table 2 Relation between Holter findings and coronary anatomy

\begin{tabular}{|c|c|c|c|c|c|c|c|c|}
\hline & \multicolumn{2}{|c|}{ Multivessel disease } & \multicolumn{2}{|c|}{ Patent infarct artery } & \multicolumn{2}{|c|}{ Three vessel disease } & \multicolumn{2}{|c|}{ Collateralisation } \\
\hline & $\begin{array}{l}\text { No } \\
(n=43) \\
n(\%)\end{array}$ & $\begin{array}{l}\text { Yes } \\
(n=51) \\
n(\%)\end{array}$ & $\begin{array}{l}\text { No } \\
(n=30) \\
n(\%)\end{array}$ & $\begin{array}{l}\text { Yes } \\
(n=60) \\
n(\%)\end{array}$ & $\begin{array}{l}\text { No } \\
(n=77) \\
n(\%)\end{array}$ & $\begin{array}{l}Y e s \\
(n=17) \\
n(\%)\end{array}$ & $\begin{array}{l}\text { No } \\
(n=66) \\
n(\%)\end{array}$ & $\begin{array}{l}\text { Yes } \\
(n=27) \\
n(\%)\end{array}$ \\
\hline $\begin{array}{l}\text { ST shift }(n=37) \\
>3 \text { Episodes of ST shift }(n=18) \\
\text { Duration of ST shift }>1 h(n=16)\end{array}$ & $\begin{array}{r}13(30 \cdot 2) \\
5(11 \cdot 6) \\
5(11 \cdot 6)\end{array}$ & $\begin{array}{l}24(47 \cdot 1) \\
13(25 \cdot 5) \\
11(21 \cdot 6)\end{array}$ & $\begin{array}{l}9(30 \cdot 0) \\
3(10 \cdot 0) \\
4(13 \cdot 3)\end{array}$ & $\begin{array}{l}25(41 \cdot 7) \\
13(21 \cdot 7) \\
11(18 \cdot 3)\end{array}$ & $\begin{array}{l}28(36 \cdot 4) \\
11(14 \cdot 3) \\
10(13 \cdot 0)\end{array}$ & $\begin{array}{l}9(52 \cdot 9) \\
7(41 \cdot 2)^{\star \star} \\
6(35 \cdot 3)^{\star}\end{array}$ & $\begin{array}{l}27(41) \\
13(20) \\
11(17)\end{array}$ & $\begin{array}{l}9(33) \\
4(15) \\
4(15)\end{array}$ \\
\hline
\end{tabular}


coronary arteriography and small patient numbers. Thus although Johnson et al found a higher prevalence of three vessel disease in patients with unstable angina who had ischaemia during Holter monitoring, ${ }^{13}$ the findings have not been confirmed by other investigators either in unstable angina ${ }^{14}$ or acute myocardial infarction. ${ }^{6}$ The available evidence, therefore, suggests that although remote ischaemia contributes to Holter ST shift early after acute coronary syndromes, other mechanisms may also play a part.

Residual ischaemia in the zone of infarction may also be important in the pathogenesis of Holter ST shift. Although there was no significant relation between Holter ST shift and patency, there was a clear trend towards it being more common in patients with a patent infarct related artery. Of the nine patients with Holter ST shift and an occluded infarct related artery, seven had a well developed collateral supply to the infarct territory. The delay between Holter monitoring and coronary arteriography, however, makes interpretation of the data difficult and limits the confidence of the conclusions that can be drawn. In particular, the possibility of late recanalisation means that at least some of the infarct related arteries found to be patent at angiography may have been occluded at the time of Holter monitoring. If ischaemia in the zone of infarction is important, the coronary morphology data suggest that dynamic mechanisms are likely to be involved. Previous work has shown that the stenosis irregularity and ulceration characteristic of complex coronary lesions represent areas of plaque fissure or rupture ${ }^{111516}$ and increases the risk of thrombotic occlusion and ischaemic events. ${ }^{17-21}$ The association between complex lesion morphology and Holter ST shift in our study, therefore, supports the hypothesis that dynamic processes (vasoconstriction, platelet aggregation, and thrombosis) are important in the pathophysiology of ischaemia after infarction. Previous studies have shown that ischaemia after infarction detected on Holter monitoring occurs at a lower heart rate than ischaemia on exercise tests; supporting the hypothesis that it may relate, at least in part, to dynamic mechanisms limiting coronary arterial supply. ${ }^{22}{ }^{23}$ This conclusion is supported by the observations of Currie and Saltissi who showed that increments in heart rate during ischaemia on Holter monitoring in the early period after infarction (six days) were less pronounced than later recordings (38 days) when demand driven ischaemia is likely to become prominent. ${ }^{24}$ Conversely, the same authors showed that in most cases ischaemia during Holter monitoring after infarction was accompanied by a rise in heart rate of $10 \mathrm{beats} / \mathrm{min}$ or more suggesting that increases in oxygen demand must play a part. ${ }^{22}$ Furthermore, the strong relation between the presence of ischaemia detected during Holter monitoring and exerciseinduced ischaemia in both stable ${ }^{1225}$ and unstable ${ }^{32}$ coronary syndromes implies that similar mechanisms must be involved. The available evidence suggests, therefore, that although periodic reductions in oxygen supply may be the dominant mechanism of ischaemia after infarction treated with thrombolysis, a complex interplay between supply and demand related factors seems likely.

In conclusion, although ST shift recorded on Holter monitoring early after myocardial infarction is clearly an ischaemic phenomenon, the underlying pathophysiology in patients treated by thrombolysis is likely to be complex and multifactorial. Thus it seems to relate both to remote ischaemia in patients with extensive coronary disease, and residual ischaemia in the zone of infarction in those with patency of the infarct related artery. In these patients, dynamic mechanisms associated with complex lesion morphology may play an important part.

1 Fox K. Silent ischaemia: clinical implications in 1988. $\mathrm{Br}$ Heart $\mathcal{f} 1988 ; 60: 363-6$

2 Petretta M, Bonaduce D, Bianchi V, et al. Characterization and prognostic significance of silent myocardia ischaemia on predischarge electrocardiographic monitoring in unselected patients with myocardial infarction. Am I Cardiol 1992;69:579-83.

3 Bonaduce D, Petretta M, Lanzillo T, et al. Prevalence and prognostic significance of silent myocardial ischaemia prognostic significance of silent myocardial ischaemia ing after acute myocardial infarction. Eur Heart $f 1991$, ing after acut

4 Currie P, Ashby D, Saltissi S. Prognostic value of ambulatory ST segment monitoring after acute myocardia infarction [abstract]. Br Heart $\mathcal{F}$ 1991;66:61.

5 Gottlieb S, Gottlieb S, Achuff S, et al. Silent ischaemia on Holter monitoring predicts mortality in high-risk pos infarction patients. $\mathscr{f} A M A 1988 ; 259: 1030-41$.

6 Ouyang P, Chandra N, Gottlieb S. Frequency and importance of silent myocardial ischaemia identified with ambulatory electrocardiographic monitoring in the early in-hospital period after acute myocardial infarction. $A m$ in Cardiol 1990;65:267-70.

7 Tzivoni D, Gavish A, Zin D, et al. Prognostic significance of ischaemic episodes in patients with previous myocarof ischaemic episodes in patients with previo
dial infarction. $A m \mathcal{F}$ Cardiol 1988;62:661-4.

8 Stevenson RN, Ranjadayalan K, Marchant BG, Timmis AD. Recurrent events after thrombolysis in acute myocardial infarction: predictive value of Holter ST analysis and treadmill stress testing [abstract]. Eur Hear f 1992;13:276.

9 The TIMI study group. The Thrombolysis in Myocardial Infarction (TIMI) trial. N Engl f Med 1985;312:932-6.

10 Rentrop KP, Cohen M, Blanke H, Phillips RA. Changes in collateral channel filling immediately after controlled coronary artery occlusion by an angioplasty balloon in human subjects. $\mathcal{F} \mathrm{Am}$ Coll Cardiol 1985;5:587-92.

11 Ambrose JA, Winters SL, Arora RR, et al. Coronary angiographic morphology in myocardial infarction: a link between the pathogenesis of unstable angina and link between the pathogenesis of unstable angina and

12 Mulcahy D, Keegan J, Crean P, et al. Silent myocardia ischaemia in chronic stable angina: a study of its frequency and characteristics in 150 patients. $\mathrm{Br}$ Heart $f$ 1988;60:417-23.

13 Johnson SM, Mauritson DR, Winniford MD, et al. Continuous electrocardiographic monitoring in patients with unstable angina pectoris: identification of high risk subgroup with severe coronary disease, variant angina, and/or impaired early prognosis. Am Heart $f 1982$ 103:4-12.

14 Gottlieb SO, Weisfeldt ML, Ouyang P, Mellits ED, Gerstenblith G. Silent ischaemia as a marker for early unfavourable outcomes in patients with unstable angina. N Engl f Med 1986;314:1214-9.

15 Levin DC Fallon TT Significance of the angiographic morphology of localised coronary stenoses: histopathomorphology of localised coronary stenoses: histop
logical correlations. Circulation 1982;66:316-20.

16 Forrester JS, Litvack F, Grundfest W, Hickey A. A perspective of coronary disease seen through the arteries of spective of coronary disease seen through

17 Ellis S, Alderman E, Cain K, Wright A, Bourassa M, Fisher L. Morphology of left anterior descending coronary territory lesions as a predictor of anterior myocardial infarction: a CASS registry study. $\mathcal{F} \mathrm{Am}$ Coll Cardiol 1989;13:1481-91

18 Bugiardini R, Pozzati A, Borghi A, et al. Angiographic morphology in unstable angina and its relation to 
transient myocardial ischaemia and hospital outcome. Am $\mathcal{F}$ Cardiol 1991;67:460-4.

19 Ambrose JA, Winter SL, Arora RR, et al. Angiographic evolution of coronary artery morphology in unstable angina. $\mathcal{F}$ Am Coll Cardiol 1986;7:472-8.

20 Langer A, Freeman MR, Armstrong PW. Relation between angiographic detectehd intracoronary thrombus and silent myocardial ischaemia in unstable angina pectoris. Am $₹$ Cardiol 1992;66:1381-2

21 Davies SW, Marchant BG, Lyons JP, et al. Irregularity of coronary lesions after thrombolysis predicts early clinical instability. F Am Coll Cardiol 1991;18:669-74.

22 Currie P, Saltissi S. Transient ischaemia after acute myocardial infarction: relationship to exercise ischaemia. Eur Heart f 1991;12:395-400.

23 Moczurad KW, Grodecki JK, Dubiel JP, Curylo AM. Silent myocardial ischaemia in Holter monitoring and exercise stress testing after a first myocardial infarction. Eur Heart f 1988;9(suppl N):114-8.

24 Currie P, Saltissi S. Transient myocardial ischaemia after acute myocardial infarction. Br Heart $\mathcal{f}$ 1990;64: 299-303.

25 Campbell S, Barry J, Rebecca GS, et al. Active transient myocardial ischaemia during daily life in symptomatic patients with positive exercise tests and coronary artery disease. Am f Cardiol 1986;57:1010-6. 